\title{
Antioxidant and gastric cytoprotective prostaglandins properties of Cassia sieberiana roots bark extract as an anti-ulcerogenic agent
}

\author{
Edmund T Nartey ${ }^{1{ }^{*} \dagger}$, Mark Ofosuhene ${ }^{2 \dagger}$, William Kudzi ${ }^{1+}$ and Caleb M Agbale ${ }^{3}$
}

\begin{abstract}
Background: Cassia sieberiana is a savannah tree with a wide phytotherapeutic application including the use of its roots in the management of various stomach disorders including gastric ulcer, stomach pains and indigestion. The aim of the study is to evaluate the antioxidant, gastric cytoprotective prostaglandins, secretory phospholipase $A_{2}$, phytochemical and acute toxicity properties of Cassia sieberiana roots bark extract in a bid to justify its phytotherapeutic applications in gastric ulcer.
\end{abstract}

Methods: Antioxidant and radical scavenging activities of the roots bark extract of Cassia sieberiana were assayed. Serum secretory phospholipase $A_{2}\left(S P L A_{2}\right)$ concentration and activity and the formation of gastric mucosal prostaglandins $E_{2}\left(P G E_{2}\right)$ and $I_{2}\left(P G I_{2}\right)$ were also assessed. Comparisons between means were performed using analysis of variance (ANOVA) followed by Students Standard Newman-Keuls post hoc analysis to determine statistical significance. $P<0.05$ was considered significant.

Results: The extract was found to possess significant ferric reducing antioxidant power and can scavenge hydroxyl radicals. The extract also possesses DPPH scavenging activity, can chelate ferrous ion and a dose-dependent protective effect against lipid peroxidation and free radical generation. Prostaglandin studies showed that the roots bark extract dose dependently increased gastric mucosal $P \mathrm{PE}_{2}$ and $P \mathrm{PG}_{2}$ levels and also decreased serum sPLA 2 activity. Phytochemical analyses suggest that the roots extract contains polyhydroxyl/phenolic substances. Acute toxicity test showed no sign of toxicity up to a dose level of $2000 \mathrm{mg} / \mathrm{kg}$ body weight p.o.

Conclusions: C. sieberiana roots extract possesses significant antioxidant and gastric cytoprotective prostaglandin properties as well as serum secretory phospholipase $A_{2}$ inhibitory activity which could be due to its content of polyhydroxy and/or phenolic substances. This may justify its use as an anti-ulcerogenic agent in traditional medicine in West Africa.

\section{Background}

Cassia sieberiana is a savannah tree with a wide application including the ethnopharmacological use of its roots in the management of various stomach disorders including gastric ulcer, stomach pains and indigestion [1]. At the Centre for Scientific Research into Plant Medicine (CSRPM) in Ghana, an aqueous suspension of the powdered roots bark is used to manage abdominal colic and pains associated with the joints. Earlier

\footnotetext{
* Correspondence: etnartey@chs.edu.gh

${ }^{\dagger}$ Equal contributors

${ }^{1}$ Centre for Tropical Clinical Pharmacology and Therapeutics, University of Ghana Medical School, P.O. Box GP 4236, Accra, Ghana

Full list of author information is available at the end of the article
}

studies we conducted indicated that the aqueous roots bark extract of $C$. sieberiana possesses anti-ulcerogenic properties against gastric ulcers induced by various methods [2].

Among the various factors implicated in the pathophysiology of gastric ulcer disease are the roles played by endogenous generation of prostaglandins (PGs) and free radicals [3]. Free radicals play fundamental roles in many physiological reactions. Due to their high reactivity, they have been implicated in the causation of some degenerative diseases including stress, NSAID and $H$. pylori induced gastric ulcers $[4,5]$. They have been shown to mediate the micro-vascular disturbance that precedes stress, NSAID or ischaemic reperfusion induced gastric mucosal 
injuries and also in the pylorus ligation model of gastric ulcers [5,6]. In addition studies have shown that certain anti-oxidants also prevent gastric ulcers [7-9].

PGs, a family of lipid compounds derived from arachidonic acid pathway mediate a wide range of physiological functions including modulation of inflammation and gastrointestinal mucosal defence. Superficial injury to the gastric mucosa is known to trigger an acute inflammatory response, characterized by the increase in blood flow, as well as by plasma exudation and recruitment into the mucosa of leukocytes [10]. While the acute inflammatory response is aimed at reducing mucosal injury, there are circumstances in which this response can be dysregulated and can contribute to mucosal injury [11]. The major prostaglandins produced by human and rodent gastric mucosa are $\mathrm{PGE}_{2}$ and $\mathrm{PGI}_{2}$ and these PGs accelerate ulcer healing in both experimental animal models and in humans $[12,13]$. The dual contribution of PGs to inflammation and mucosal defence present a challenge to the development of anti-inflammatory drugs.

Phospholipids also play an important role in the preservation of gastrointestinal homeostasis [14]. Phospholipase $\mathrm{A}_{2}$ $\left(\mathrm{PLA}_{2}\right)$, an enzyme is capable of hydrolyzing membrane phospholipids, which in the presence of high gastric acidity leads to mucosal damage. PLA 2 mediated hydrolysis of membrane lipids results in membrane perturbation, cell degranulation and stripping of cell surface receptors resulting in gastric ulcer. High concentrations of $\mathrm{PLA}_{2}$ have been reported in gastric mucosa [15] and $\mathrm{PLA}_{2}$ inhibitors are known to modulate proton conductance across cell membranes [16] and thus can offer gastric mucus protection from enzymatic breakdown. As a result of our earlier study on the phytotherapeutic ability of the roots bark of C. sieberiana as an anti-ulcerogenic agent, this study was conducted to assess the anti-oxidative (in vitro) and gastric mucosal prostaglandin properties of the roots bark extract of the plant.

\section{Methods}

\section{Preparation of roots bark extract}

Fresh roots of C. sieberiana (Cassia kotschyana Oliv.) were obtained from the grounds of the University of Ghana. The plant was identified and authenticated at the Ghana Herbarium, University of Ghana, Ghana. The chopped fresh roots bark $(750 \mathrm{~g})$ were grounded and mixed with $1 \mathrm{~L}$ of water and left to stand overnight. The resulting concoction was evaporated under reduced pressure at $30^{\circ} \mathrm{C}$ and the concentrate freeze-dried to yield solid material. The freeze-dried roots bark extract was stored at $4^{\circ} \mathrm{C}$ and used within 4 weeks of production.

\section{Animals}

Male guinea pigs weighing $318 \pm 30.3 \mathrm{~g}$ (mean \pm S.D) were used for the prostaglandin studies. They were feed mainly on the leaves of Panicum maximum (Elephant grass) supplemented with standard laboratory diet (GAFCO, Tema, Ghana). Fisher 344 $\left(\mathrm{F}_{344}\right)$ rats weighing $230.3 \pm 14.5 \mathrm{~g}$ (mean \pm S.D) of both sexes were used for the acute oral toxicity studies. They were also raised on standard laboratory diet (GAFCO, Tema, Ghana). The animal experimentation described in this study was approved by the Ethical and Protocol Review Committee of Noguchi Memorial Institute for Medical Research of the University of Ghana and was conducted in accordance with internationally accepted principles for laboratory animal use and care.

\section{Chemicals and reagents}

L-ascorbic acid (LAA) was obtained from Sigma Chemical Company, St. Loius, U.S.A. All of the reagents for the antioxidant studies were obtained from Fluka Chemie, Switzerland. The enzyme immunoassay kits for prostaglandin $\mathrm{E}_{2}$ (Cat \# 514010) and prostaglandin $\mathrm{I}_{2}$ (assayed as 6-keto $\mathrm{PGF}_{1 \alpha}$, Cat \# 515211) as well as secretory phospholipase $\mathrm{A}_{2}$ (human Type IIa, Cat \# 585000) and secretory phospholipase $A_{2}$ activity (Type IIa, Cat \# 765001) were obtained from Cayman Chemical Company (Am Arbor, U.S.A.). Arachidonic acid, reduced glutathione (GSH) and bovine serum albumin (BSA) were obtained from Sigma Chemical Company (St. Louis, MO, U.S.A.).

\section{In vitro antioxidant studies}

All of the reagents for the antioxidant studies were prepared in deionised water to eliminate the contamination of metal ions. Total phenolic concentrations were determined as described by AOAC [17]. Total reducing power of the plant extract was determined by the method of Yildirim et al. [18]. DPPH radical scavenging activity was determined by the method of Zhu et al. [19]. Antioxidant activity in a haemoglobin-induced linoleic acid system of the roots extract was determined by a modified photometry method as described by Kuo et al. [20]. The hydroxyl scavenging activity was measured by studying the competition between deoxyribose and the extract for hydroxyl radicals generated from the $\mathrm{Fe}^{3+} /$ ascorbate/ EDTA/ $\mathrm{H}_{2} \mathrm{O}_{2}$ system [21]. Ferrous ion chelating effect was determined according to the method of Dinis et al. [22]. These assays were done in triplicate and L-ascorbic acid (LAA) was used as positive control.

\section{Gastric prostaglandins studies Administration of plant extract}

Different concentrations of the roots extract $250 \mathrm{mg} / \mathrm{kg}$, $500 \mathrm{mg} / \mathrm{kg}$ and $750 \mathrm{mg} / \mathrm{kg}$ body weight, suspended in water (as vehicle) in a total volume of $2.0 \mathrm{~mL}$ were administered orally to three groups of guinea pigs made up of 5 animals per group. Treatment was repeated every 
24 hours for 28 consecutive days. The control group received the vehicle instead of the roots extract.

\section{Blood sampling}

A day after the administration of the last dose of the plant extract, each animal was anaesthetised using sodium pentobarbitone $(60 \mathrm{mg} / \mathrm{kg}$ body weight, i.p). A total volume of $5 \mathrm{~mL}$ of blood was obtained from each anaesthetised animal by cardiac puncture and a sample of $100 \mu \mathrm{L}$ is diluted 1 in 9 using pre-chilled $25 \mathrm{mM}$ Tris$\mathrm{HCl}$. This portion was used for the determination of serum secretory phospolipase $\mathrm{A}_{2}\left(\mathrm{sPLA}_{2}\right)$ concentration. A different portion of the obtained blood was allowed to clot and the serum used to estimate sPLA $A_{2}$ activity and protein content. The protein content in serum was determined by the Folin-Lowry method [23].

\section{Eicosanoid biosynthesis and assay}

Briefly after euthanizing the animals, the stomach were rinsed in pre-chilled $0.15 \mathrm{M} \mathrm{KCl}$ and then homogenised using $0.25 \mathrm{M}$ sucrose-10 mM Tris- $\mathrm{HCl}$ (pH 7.5). The homogenate was centrifuged at $10,000 \mathrm{~g}$ for $20 \mathrm{~min}$ at $4^{\circ} \mathrm{C}$ and the supernatant centrifuged again at 105,000 $\mathrm{g}$ for $60 \mathrm{~min}$ at $4{ }^{\circ} \mathrm{C}$. The pellet was homogenised in $0.1 \mathrm{M} \mathrm{K}_{2} \mathrm{PO}_{4}$ buffer (pH 7.6). The eicosanoids prostaglandin $\mathrm{E}_{2}\left(\mathrm{PGE}_{2}\right)$ and prostaglandin $\mathrm{I}_{2}\left(\mathrm{PGI}_{2}\right)$ (assayed as 6-keto $\mathrm{PGF}_{1 \alpha}$ ) were biosynthesised using GSH as co-factor in the cyclooxygenase reaction. Reactions were terminated after 5 minutes using $100 \mu \mathrm{L}$ of $1.0 \mathrm{M}$ citric acid and assayed with ELISA kit from Cayman Chemical Company (Am Arbor, U.S.A.).

\section{Secretory phospholipase $A_{2}$ concentration and activity}

Secretory phospholipase $A_{2}$ concentration and secretory phospholipase $\mathrm{A}_{2}$ activity in the serum were assayed using kits (Cat \# 585000 and Cat \# 765001 respectively) from Cayman Chemical Company (Am Arbor, U.S.A.).

\section{Phytochemical analyses}

Standard phyto-chemical tests were used for the detection of tannins, saponins, flavonoids and anthraquinones in the extract [24]. Thin layer chromatography was also conducted on the plant extract using different mobile phase systems and silica gel $60 \mathrm{~F}_{254}$ as the stationary phase. The chromatograms developed were viewed under daylight, UV light and vaporised iodine. The resolved components under UV light were treated with $0.1 \mathrm{mM} \mathrm{FeCl}_{3}$.

\section{Acute toxicity}

Acute oral toxicity study was performed as per OECD423 guidelines (acute oral toxicity-acute toxic class method). Specific pathogen free $\mathrm{F}_{344}$ rats of either sex selected by random sampling technique were fasted overnight with water ad libitum after which the extracts (dissolved in water) were administered orally by gastric instillation beginning from a dose of $5 \mathrm{mg} / \mathrm{kg}$ body weight. The rats were observed for death within 48 hours after extract administration and surviving animals observed for 14 days for weight changes, lethargy and behavioural modifications. If mortality was not observed, the procedure was repeated with higher doses such as 50,300 and 600 up to $2000 \mathrm{mg} / \mathrm{kg}$ body weight.

\section{Statistical analysis}

Comparisons between means were performed using analysis of variance (ANOVA) followed by Students Standard Newman-Keuls post hoc analysis to determine statistical significance. $\mathrm{P}<0.05$ was considered significant.

\section{Results}

\section{Antioxidant studies}

\section{Amount of total phenolic compounds}

Analyses of an amount of $200 \mu \mathrm{g}$ of freeze-dried extract of C. sieberiana yielded $75.32 \pm 0.52$ of gallic acid equivalents of polyphenols. Therefore total phenolic compounds constituted $37.66 \pm 0.27 \%$ of C. sieberiana roots bark extract.

\section{Reducing power}

The reducing power of the roots extract of C. sieberiana and LAA as reference compound are shown in Figure 1. The graph shows that the reducing power increased with increasing concentration of C. sieberiana or LAA up to a concentration of $0.8 \mathrm{mg} / \mathrm{mL}$ after which there was no further increase in reducing power with increasing concentration of C. sieberiana extract or LAA. Analysis of the data indicated that below a concentration of $0.6 \mathrm{mg} / \mathrm{mL}$ for both C. sieberiana and LAA, significantly higher concentration of C. sieberiana than LAA was required to produce the same absorbance. The concentrations to attain one absorbance unit at $700 \mathrm{~nm}$ were $0.28 \pm 0.03 \mathrm{mg} / \mathrm{mL}$ for C. sieberiana and $0.26 \pm 0.02 \mathrm{mg} / \mathrm{mL}$ for LAA.

\section{DPPH radical scavenging activity}

In the current study the scavenging activities of DPPH exerted by $C$. sieberiana and LAA shows a linear response curve (Figure 2) and the $\mathrm{IC}_{50}$ estimated for C. sieberiana and LAA were $0.095 \pm 0.006 \mathrm{mg} / \mathrm{mL}$ and $0.06 \pm 0.004 \mathrm{mg} /$ $\mathrm{mL}$ respectively. This significantly different $\mathrm{IC}_{50}$ value of the crude extract was however $63.2 \%$ that of LAA.

\section{Scavenging effect on hydroxyl radical}

In this study, the roots extract was able to achieve a $62 \%$ maximum scavenging activity when its concentration was more than $10 \mathrm{mg} / \mathrm{mL}$ (Figure 3). Nevertheless, LAA had about $70 \%$ scavenging activity at the low concentration of $0.02 \mathrm{mg} / \mathrm{mL}$. The $\mathrm{IC}_{50}$ estimated for $C$. sieberiana was $0.04 \pm 0.006 \mathrm{mg} / \mathrm{mL}$ whilst that for LAA was $0.01 \pm 0.002 \mathrm{mg} / \mathrm{mL}$. 


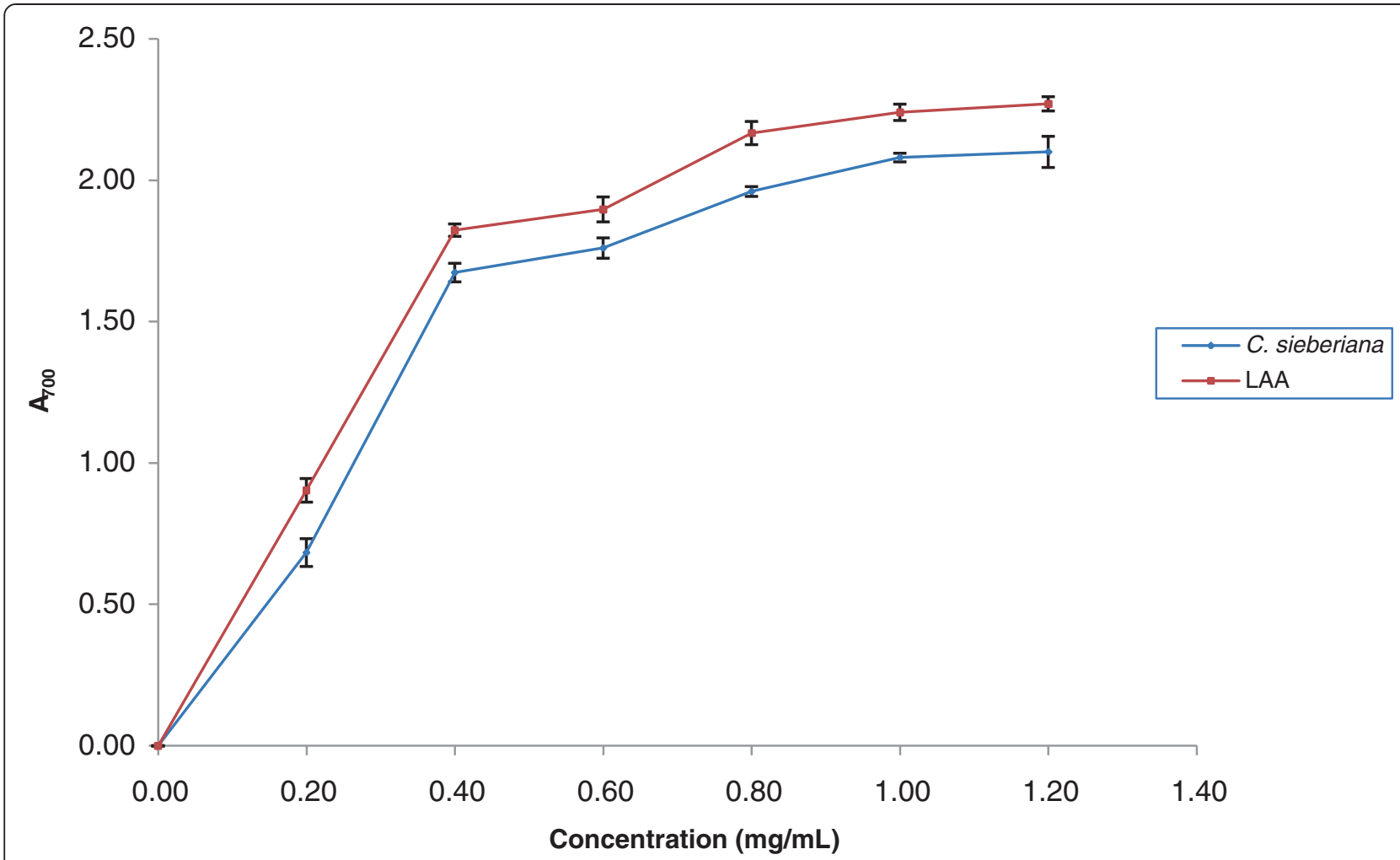

Figure 1 Reducing power of $C$. sieberiana roots bark extract. $L$-ascorbic acid (LAA) was used as a reference compound. Results are means \pm SEM of $n=3$.

\section{Antioxidant activity in a haemoglobin-induced linoleic acid system}

As shown in Figure 4 the antioxidant activity was dose dependent and reached a plateau (about 77-87\% inhibition) when the concentration of $C$. sieberiana exceeded $0.06 \mathrm{mg} / \mathrm{mL}$. This result indicates that the antioxidant activity of $C$ sieberiana is only about $17 \%$ that of LAA as shown by the peroxidation in the presence of $1 \mathrm{mM}$ linoleic acid. The $\mathrm{IC}_{50}$ estimated for $C$. sieberiana was $0.012 \pm 0.004 \mathrm{mg} / \mathrm{mL}$ and that for LAA was $0.006 \pm 0.002 \mathrm{mg} / \mathrm{mL}$.

\section{Ferrous ion chelating effect}

The ferrous ion chelating activity of the C. sieberiana roots extract shows a linear response curve and graph analysis shows $\mathrm{IC}_{50}$ estimation was $3.20 \pm 0.24 \mathrm{mg} / \mathrm{mL}$ for $C$. sieberiana and $0.28 \pm 0.024 \mathrm{mg} / \mathrm{mL}$ for LAA (Figure 5 ).

\section{$P E_{2}, P G I_{2}$ and $s P L A_{2}$ studies}

Daily administration of the roots extract for 28 days produced a dose dependent increase in the amounts of gastric mucosal $\mathrm{PGE}_{2}$ and 6-keto $\mathrm{PGF}_{1 \alpha}$ synthesised (Table 1). Compared with the control, $\mathrm{PGE}_{2}$ increased by $37.7 \%$ in the extract low dose (250 $\mathrm{mg} / \mathrm{kg}$ body weight), $64.7 \%$ in the extract medium dose (500 mg/ $\mathrm{kg}$ body weight) and $82.4 \%$ in the extract high dose (750 mg/kg body weight).
All the doses of the roots extract produced significant increases in 6-keto $\mathrm{PGF}_{1 \alpha}$ by $28.3 \%$ in the low dose, $61.7 \%$ in the medium dose and $88.6 \%$ in the high dose.

Oral administration of the roots extract also produced a significant inhibition of serum sPLA 2 activity but no significant change in the amount of serum $\mathrm{SPLA}_{2}$ protein. Compared with the control, the low dose produced $21.2 \%$ decrease, whilst the medium dose and the high dose produced $31.3 \%$ and $60.2 \%$ decrease in serum sPLA 2 activity respectively.

\section{Phytochemical screening}

Phytochemical screening revealed the presence of saponins, flavonoids, anthraquinones and tannins in the roots extract. Thin layer chromatography revealed by their reaction with $\mathrm{FeCl}_{3}$ and their fluorescence under UV-light indicated that the roots extract contains flavonol/flavonoid/flavone or related compounds with polyhydroxy and/ or phenolic groups.

\section{Acute toxicity}

In $\mathrm{F}_{344}$ rats of either sex, the extracts $(5-2000 \mathrm{mg} / \mathrm{kg}$, $\mathrm{p}$. o) given as a single dose did not produce any signs of acute toxicity. No mortality was observed during the study period of 14 days and at necropsy, no gross changes in viscera were observed in the treated groups. 


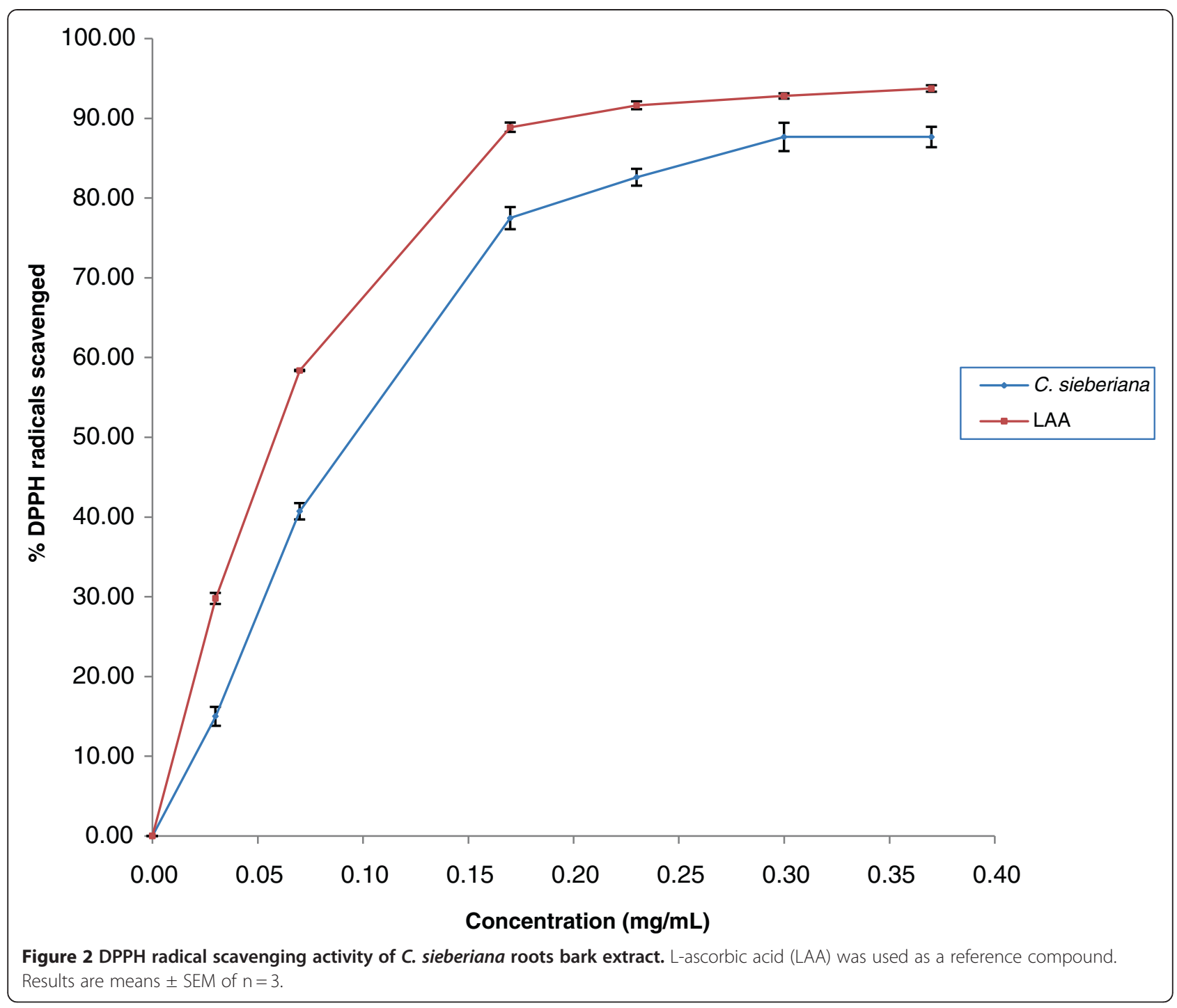

\section{Discussion}

The present study was undertaken to investigate the antioxidant and gastric cytoprotective prostaglandin properties of the aqueous roots extract of $C$. sieberiana, which we had previously demonstrated to possess antiulcerogenic properties. Gastric ulcer disease is a multifactorial disease and among the various properties implicated in its pathophysiology is the role played by free radicals. Hence antioxidants which can scavenge free radicals are expected to heal or prevent gastric ulcers. Several methods developed to measure the efficiency of antioxidants focus on different mechanisms of the oxidant defence system. In most of the systems, irrespective of the stage in the oxidative chain in which the antioxidant action is measured, most non-enzymatic anti-oxidative activity is mediated by redox reactions. The redox potentials of compounds are related to their antioxidant activity against free radicals such as peroxyl or hydroxyl radicals, which have more positive redox potentials [25]. As shown in Figure 1 the reducing power increased as the extract concentration increased indicating some compounds in the roots extract were both electron donors and could react with free radicals to converts them into more stable products to terminate radical chain reactions. This result indicates that although the reducing power of LAA was slightly higher it was not significantly different from that of C. sieberiana $(\mathrm{p}>0.05)$. The significant reducing powers recoded therefore suggested that the roots extract of C. sieberiana would have significant antioxidant action which was subsequently confirmed by its scavenging action of free radicals generated by DPPH.

In solution, DPPH generates free radicals whose odd electrons become paired off in the presence of a hydrogen donor. The DPPH radical has been widely used to test the free radicals scavenging ability of various natural 


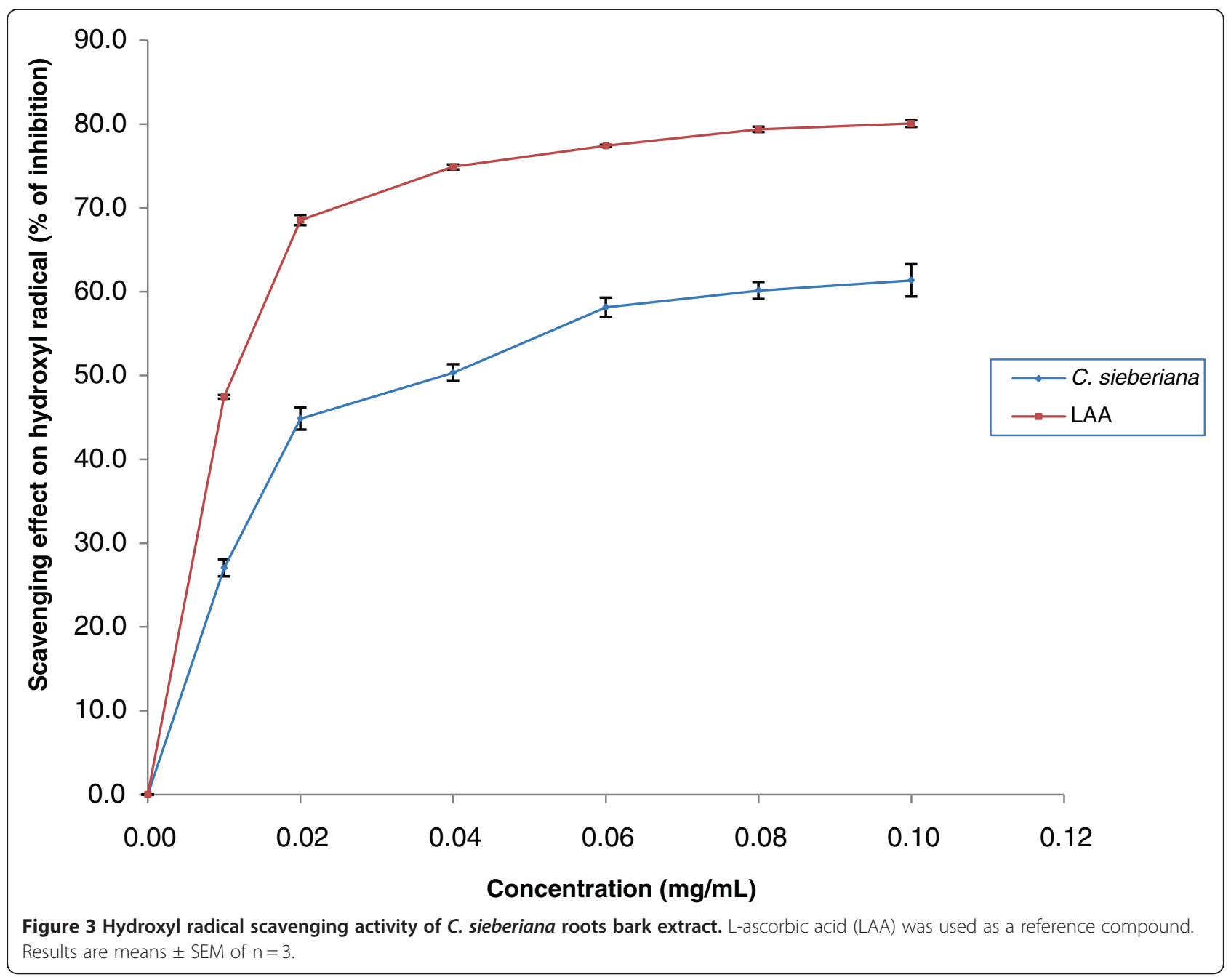

products and has been accepted as a model compound for free radicals originating in lipids [26]. In DPPH assay the lower the $\mathrm{IC}_{50}$, the better it is able to scavenge the radicals, particularly peroxy radicals which are the propagators of the auto-oxidation of lipid molecules and thereby break the free radical chain reaction. Like the reducing power, at the $\mathrm{IC}_{50}$ of $0.075 \pm 0.006 \mathrm{mg} / \mathrm{mL}$, the DPPH scavenging activity of the crude extract was $63.2 \%$ that of LAA which indicates that the roots extract contains compounds that have strong antioxidant properties. Hydroxyl radical is the principal contributor for tissue injury. The deoxyribose method is used in determining the rate constants of reactions involving hydroxyl radicals. The reaction involves the incubation of a mixture of $\mathrm{FeCl}_{3}$-EDTA, $\mathrm{H}_{2} \mathrm{O}_{2}$ and ascorbate with deoxyribose in phosphate buffer ( $\mathrm{pH}$ 7.4). The hydroxyl radicals generated from the mixture attack the deoxyribose and result in a series of reactions that cause the formation of MDA. A hydroxyl radical scavenger added to the reaction mixture will therefore compete with deoxyribose for the availability of hydroxyl radicals, thereby reducing the amount of MDA formed. In this study, the roots extract of C. sieberiana was able to achieve a $62 \%$ maximum scavenging activity indicating that it contains compounds that inhibit hydroxyl scavenging activity.

Lipid peroxidation has been implicated in the pathogenesis of various diseases including gastric ulcer disease in both humans [27] and experimental animals [28]. It is well established that bio-enzymes are very much susceptible to lipid peroxides, which is considered to be the starting point of many degenerative processes. This result indicates that the antioxidant activity of $C$ sieberiana is only about $17 \%$ that of LAA as shown by the peroxidation in the presence of $1 \mathrm{mM}$ linoleic acid which was significantly lower compared with LAA. The chelating ability of the extract measures how effective the compounds in it can compete with ferrozine for $\mathrm{Fe}^{2+}$. The $\mathrm{Fe}^{2+}$-ferrozine complex has maximum absorbance at $562 \mathrm{~nm}$ and a large decrease in absorbance indicates strong chelating power. By forming a stable $\mathrm{Fe}^{2+}$ chelate, an extract with high chelating power reduces the free $\mathrm{Fe}^{2}$ ${ }^{+}$concentration thus decreasing the extent of Fenton 


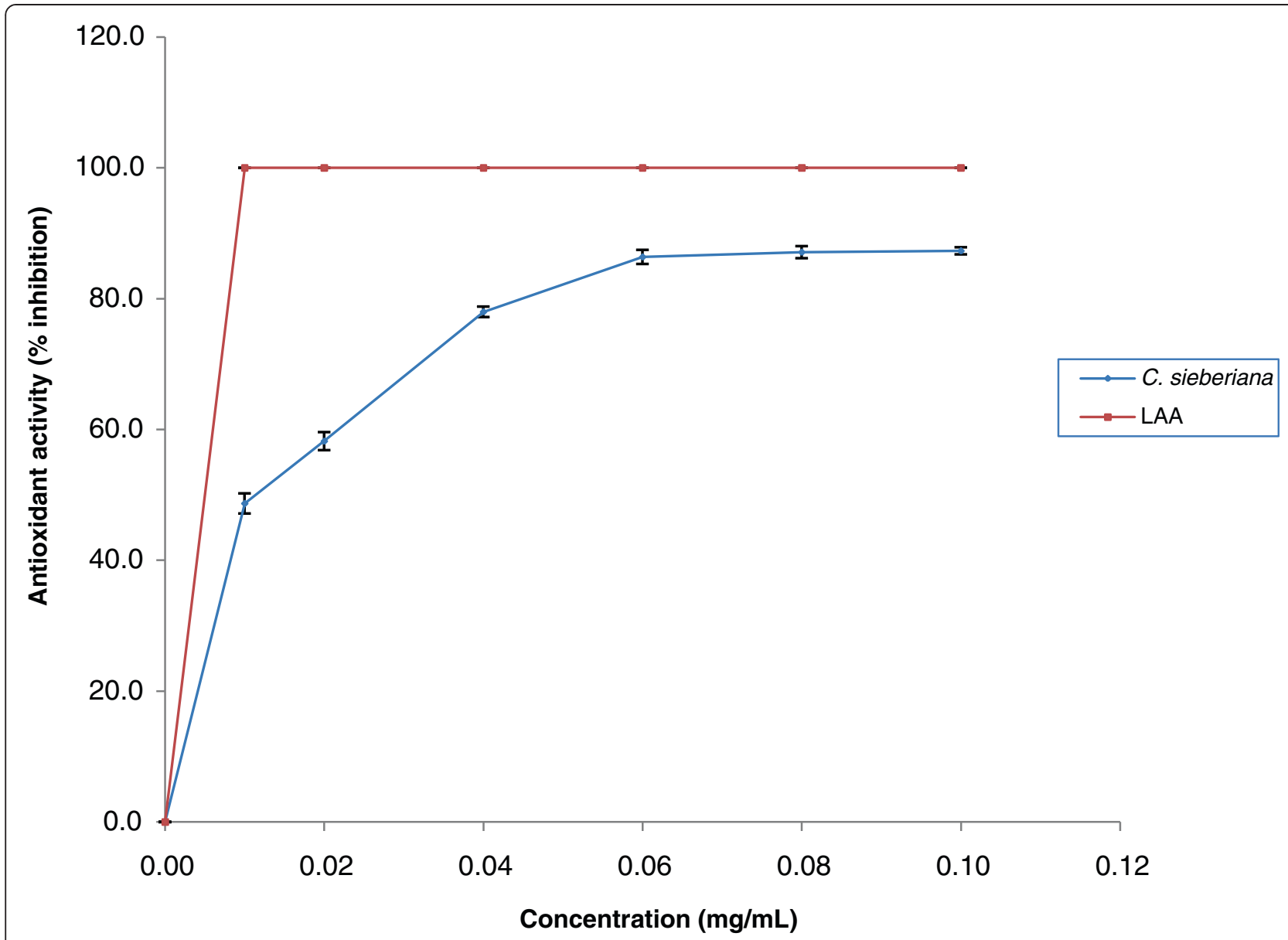

Figure 4 Antioxidant activity of $C$. sieberiana roots bark extract against linoleic acid peroxidation induced by haemoglobin. $L$-ascorbic acid (LAA) was used as a reference compound. Results are means \pm SEM of $n=3$.

reaction which is implicated in many diseases. The results indicate that the crude roots extract can chelate free $\mathrm{Fe}^{2+}$.

The observed antioxidant activity is significant because free radicals have been implicated to mediate in stress, NSAID and H. Pylori induced gastric ulcers [5,29]. Neutrophil adherence to the endothelium of gastric microcirculation has also been shown to be critical in mucosal injury in animals and such adherence is believed to liberate oxygen radicals, resulting in the release of proteases and obstructing capillary blood flow or causing lipid peroxidation and damaging cell membranes [30]. Therefore the reported anti-ulcer activity of the roots extract of $C$. sieberiana could be due in part to its strong reducing and antioxidant properties.

Phytochemical analysis detected alkaloids, saponins, anthraquinones, tannins and flavonoids in the C. sieberiana roots extract. TLC spots revealed by their reaction with ferric chloride and their fluorescence under UV light indicated that flavonol/flavonoid/flavone or related compounds with polyhydroxy and/or phenolic groups constituted major chemical substances in the roots extract. Evidence of the presence of flavonol/flavonoid/flavone or a related compound with polyhydroxy and/or phenolic groups is consistent with the significant antioxidant effect of the roots extract. Flavonoids or polyphenolic substances exert antioxidant actions by scavenging free radicals, chelating metal ions or inhibiting enzyme systems that generate free radicals. Several studies demonstrated that flavonoids from various plants are reportedly capable of preventing the occurrence of gastric ulcer. This may take place through an increase in the amounts of neutral glycoproteins and in prostaglandin concentrations, and inhibition of histamine secretion from mast cells by inhibition of histidine decarboxylase, thus reducing stimulation of $\mathrm{H}_{2}$ receptors, or by secretion of prostaglandin-like compounds [31]. Another possible mechanism of action for inhibiting ulcer occurrences is by decreasing pepsin secretion and activity. In addition, several studies cited by Middleton and Kandaswami [32], indicate that certain flavonoids have anti-ulcer activity with some having direct mucosal 


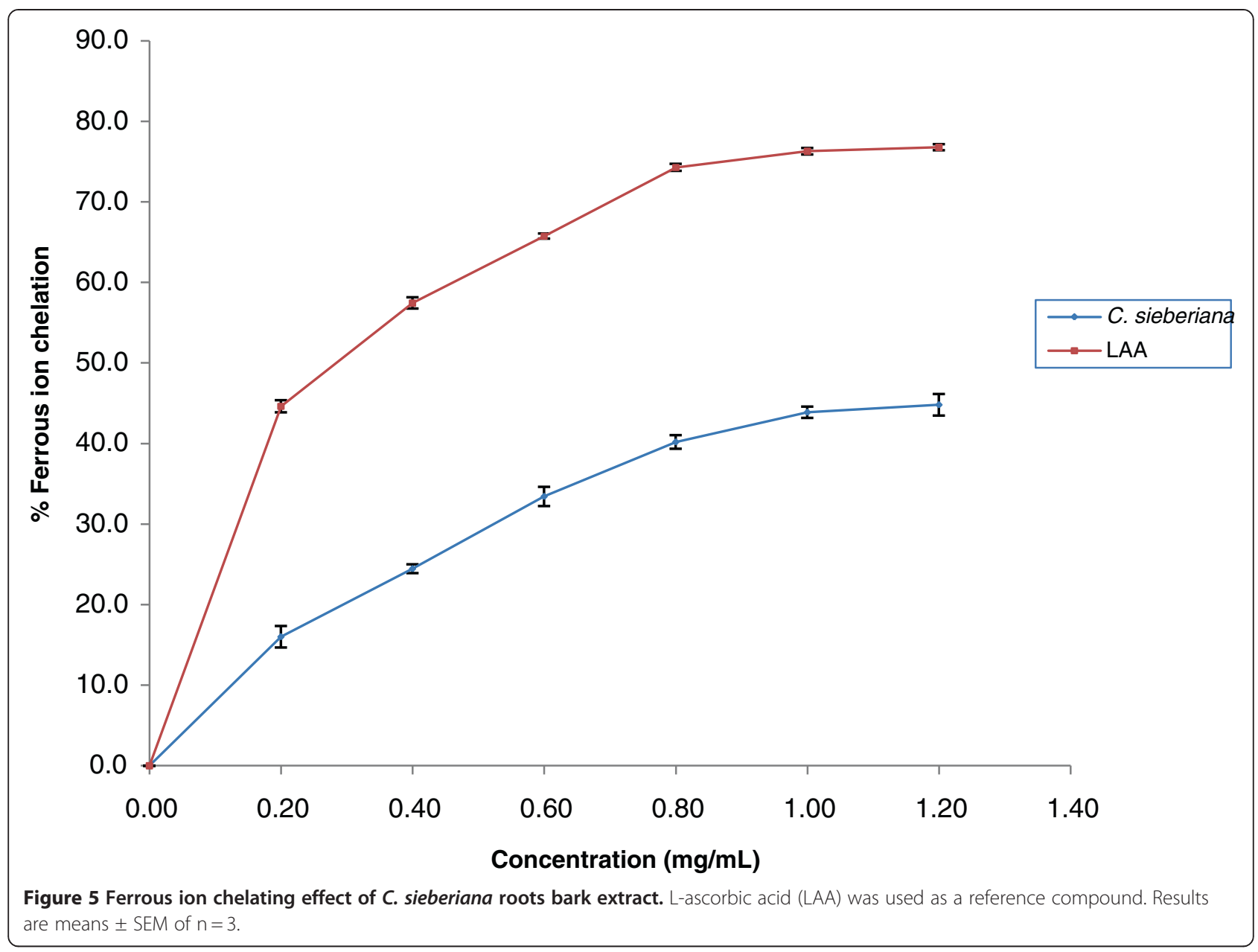

protection activity similar to that of prostaglandins. This suggests that flavonoids and/or polyphenols may be responsible for the reported gastric mucus protection and anti-ulcer properties of the roots bark extract of $C$. sieberiana.

The major prostaglandins produced by human and rodent gastric mucosa are $\mathrm{PGE}_{2}$ and $\mathrm{PGI}_{2}$ which are vasodilators in the gastrointestinal mucosa [11]. The vasodilatory properties of these two molecules may increase mucus production and reduce acid and pepsin levels in the stomach, thereby make an important contribution to gastric mucosal defence and facilitate the repair of pre-existing ulcers in the gastrointestinal mucosa [33,34]. The present results show that the significant dose-dependent increase in gastric mucosal $\mathrm{PGE}_{2}$ and $\mathrm{PGI}_{2}(82.4 \%$ and $88.6 \%$ respectively in the high dose) in the absence of induced gastric ulcers is an indicator of anti-ulcerogenic activity of the roots bark extract. These results confirm an earlier study [2] on the antiulcerogenic properties of the roots bark extract which showed that its gastric cytoprotective effect in rats was reduced significantly by pre-treatment with indomethacin, an NSAID prostaglandin inhibitor.
The inflammatory process which occurs during gastric ulceration is also known to be a key component of mucosal defence against exogenous and endogenous factors. However, while the acute inflammatory response is aimed at reducing mucosal injury, some of the inflammatory mediators released increase the susceptibility of the stomach to damage induced by NSAIDs or other topical irritants, and thereby contributes to the generation of mucosal injury in certain circumstances [11]. Several of these inflammatory mediators including histamine, tumor necrosis factor- $\alpha$, platelet-activating factor, interleukin- 1 , interleukin- 8 and leukotriene $B_{4}$ have been shown to be down-regulated by endogenous generation of prostaglandins [11]. In addition prostaglandins are also potent inhibitors of leukocyte adherence to the vascular endothelium which is a hallmark of inflammation such that leukocyte adherence that occurs within the gastrointestinal microcirculation following administration of an NSAID can be prevented by prostaglandin administration $[35,36]$. It is imperative to note that activated inflammatory cells may also be potential sources of free radicals [37] which further aggravate the damaged gastric mucosa. 
Table 1 Effect of roots bark extract of $C$. sieberiana on mucosal PGE 2 and 6-keto $\mathrm{PGF}_{1 a}$ levels and serum $\mathrm{SPA}_{2}$ activity in guinea pigs

\begin{tabular}{|c|c|c|c|c|}
\hline Treatment & $\begin{array}{c}\text { Dose } \\
(\mathrm{mg} / \mathrm{kg})\end{array}$ & $\begin{array}{c}\mathrm{PGE}_{2} \\
(\mathrm{pg} / \mathrm{mL}) \\
(\text { Mean } \pm \text { S.E.M })\end{array}$ & $\begin{array}{c}\text { 6-keto PGF } 1 a \\
(\mathrm{pg} / \mathrm{mL}) \\
\text { (Mean } \pm \text { S.E.M) }\end{array}$ & $\begin{array}{c}\text { sPLA }_{2} \\
\text { activity } \\
(\text { nmol/min } / \mathrm{mL}) \\
\text { (Mean } \pm \text { S.E.M) }\end{array}$ \\
\hline Control & vehicle & $0.17 \pm 0.02$ & $2.10 \pm 0.19$ & $26.44 \pm 0.69$ \\
\hline Extract & 250 & $0.23 \pm 0.01^{*}$ & $2.69 \pm 0.08^{*}$ & $20.84 \pm 0.65^{*}$ \\
\hline " & 500 & $0.28 \pm 0.02^{\dagger}$ & $3.39 \pm 0.34^{*}$ & $18.16 \pm 0.68^{*}$ \\
\hline$"$ & 750 & $0.31 \pm 0.02^{+}$ & $3.95 \pm 0.19^{*}$ & $10.52 \pm 0.52 *$ \\
\hline
\end{tabular}

${ }^{*} \mathrm{p}<0.05$, statistically significant relative to control.

$+\mathrm{p}<0.01$, statistically significant relative to control.

$\$ \mathrm{p}<0.001$, statistically significant relative to control.

This may be a potential mechanism of action of anti-oxidants as anti-ulcerogenic agents.

The roots extract did not show decline of $\mathrm{SPLA}_{2}$ protein; however, enzymatic activity of sPLA $\mathrm{S}_{2}$ in serum was definitely inhibited. Thus, the impact may be on the enzymesubstrate level possibly by blunting $\mathrm{sPLA}_{2}$ interaction with its substrates rather than on the synthesis of sPLA $\mathrm{P}_{2}$. It was expected that the stimulation of endogenous generation of gastric mucosal $\mathrm{PGE}_{2}$ and $\mathrm{PGI}_{2}$ will be coupled with an increase of arachidonic acid signaling as a result of stimulated $\mathrm{sPLA}_{2}$. The stimulation of endogenous generation of gastric mucosal $\mathrm{PGE}_{2}$ and $\mathrm{PGI}_{2}$ despite the inhibition of serum sPLA $_{2}$ is interesting. An important clue may lie in the fact that the study measured sPLA ${ }_{2}$ in the serum and not in the stomach homogenate hence it is possible the extract is exerting its effect selectively at the two different locations due to the various isoforms of $\mathrm{sPLA}_{2}$ discovered $[38,39]$. However, the inhibition of sPLA $\mathrm{P}_{2}$ in the serum confirms an earlier report which suggests that the inhibition of serum sPLA $_{2}$ by C. sieberiana roots bark extract may be partly responsible for its therapeutic use as an anti-asthmatic and anti-inflammatory agent [40]. We are currently conducting studies into the effect of different fractionated portions of the extract on $\mathrm{sPLA}_{2}$ activity and expression in different tissues in a bid to elucidate its mechanism of action.

Despite these findings, inhibition of gastric mucosal sPLA $_{2}$ activity may indicate anti-ulcerogenic abilities. Ischemic insult to intestinal mucosa causes excessive production of oxygen derived free radicals (ODFR) that may initiate a chain of reactions in membrane-bound lipids leading to lipid peroxidation and PLA $_{2}$ activation [41,42]. Inhibition of this cascade by scavenging ODFR and/or inhibiting $\mathrm{sPLA}_{2}$ could therefore be an effective tool to protect gastrointestinal mucosa against chemically induced lesions.

\section{Conclusions}

Antioxidant properties can be primary or secondary. Primary antioxidants scavenge radicals to inhibit chain initiation and break chain propagation. Secondary antioxidants suppress the formation of radicals and protect against oxidative damage by binding to metal ions strongly. Primary antioxidant properties are generally measured by $\mathrm{DPPH}$ assay and ferric reducing antioxidant power whilst secondary antioxidant properties is generally measured by the ferrous ion chelating activity which measures the chelating ability of the extract. In this study we demonstrated that roots bark extract of $C$. sieberiana have both DPPH scavenging activity and ferric reducing power and can scavenge hydroxyl radicals. The extract was also able to arrest lipid peroxidation and chelate ferrous ion. The roots extract therefore do possess both primary and secondary antioxidant properties which may be due to the high content of phenolic compounds. The roots extract was responsible for the observed stimulation of endogenous generation of gastric mucosal $\mathrm{PGE}_{2}$ and $\mathrm{PGI}_{2}$, and the inhibition of sPLA $_{2}$ activity in serum. These findings suggest that the plant extract contains bimolecules which has high antioxidant properties and can stimulate the endogenous generation of gastric mucosal $\mathrm{PGE}_{2}$ and $\mathrm{PGI}_{2}$ which may be responsible for the therapeutic use as an anti-ulcer agent. The extract also showed no sign of acute toxicity at a dose of $2000 \mathrm{mg} / \mathrm{kg}$ body weight p.o. At present, it remains uncertain how the plant extract can inhibit serum $\mathrm{SPLA}_{2}$ but stimulate endogenous generation of gastric mucosal $\mathrm{PGE}_{2}$ and $\mathrm{PGI}_{2}$ and further studies are currently underway to clarify this by investigating the effect of different fractions of the extract on $\mathrm{SPLA}_{2}$ activity and expression in different tissues.

\section{Competing interests}

The authors declare that they have no competing interests.

\section{Authors' contributions}

ETN and MO worked in the conception and the article final composition. WK and CMA contributed in the methods, in analysing results and revising it critically. All the authors read and approved the final manuscript.

\section{Author details}

${ }^{1}$ Centre for Tropical Clinical Pharmacology and Therapeutics, University of Ghana Medical School, P.O. Box GP 4236, Accra, Ghana. 'Department of Clinical Pathology, Noguchi Memorial Institute for Medical Research, University of Ghana, P. O. Box LG 581, Legon, Ghana. ${ }^{3}$ Department of Biochemistry, School of Biological Sciences, University of Cape Coast, Cape Coast, Ghana.

Received: 16 September 2011 Accepted: 10 May 2012 Published: 20 May 2012

\section{References}

1. Abbiw DK: Portions and Medicine. In Useful plants of Ghana. London: Intermediate Technology Publications; 1990:118-205.

2. Nartey ET, Addo PG, Ofosuhene M, Okine LK, Nyarko AK: The effect of Cassia sieberiana roots bark extract on various experimental gastric ulcer models in rats. J Phytomed Ther 2009, 14:53-59.

3. Toma W, Graciosa JS, Andrade FDP, Hiruma-Lima CA, Vilegas W, Souza-Brito ARM: Antiulcerogenic activity of four extracts from the bark of Quassia amora L. (Simaroubaceae). Biol Pharm Bull 2002, 25(9):1151-1155.

4. Gülçin I, Bursal E, Sehitoğlu MH, Bilsel M, Gören AC: Polyphenol contents and antioxidant activity of lyophilized aqueous extract of propolis from Erzurum, Turkey. Food Chem Toxicol 2010, 48(8-9):2227-2238. 
5. Rastogi L, Patnaik GK, Dikshit M: Free radicals and antioxidants status following pylorus ligation induced gastric mucosal injury in rats. Pharm Res 1998, 38:125-132.

6. Das D, Banerjee RK: Effect of stress on the antioxidant enzymes and gastric ulceration. Mol Cell Biochem 1993, 125:115-125.

7. Karmeli F, Okon E, Rachmilewitz D: Sulphydryl blocker induced gastric damage is ameliorated by scavenging of free radicals. Gut 1996, 38:826832.

8. Rachmilewitz D, Karmeli F, Okon E, Samuni A: A novel anti-ulcerogenic stable radical prevents gastric mucosal lesions in rats. Gut 1994, 35:1181-1188.

9. Gülçin I: Antioxidant properties of resveratrol: a structure-activity insight. Innov Food Sci Emerg Technol 2010, 11(1):210-218.

10. Martin GR, Wallace JL: Gastrointestinal inflammation: a central component of mucosal defense and repair. Exp Biol Med 2006, 231:130-137.

11. Wallace JL: Prostaglandins, NSAIDs, and gastric mucosal protection: why doesn't the stomach digest itself? Physio/ Rev 2008, 88:1547-1565.

12. Hawthorne AB, Mahida YR, Cole AT, Hawkey $C J$ : Aspirin induced gastric mucosal damage: prevention by enteric-coating and relation to prostaglandin synthesis. Br J Clin Pharmacol 1991, 32:77-83.

13. Sontag SJ, Schnell TG, Budiman-Mak E, Adelman K, Fleischmann R, Cohen S, Roth SH, Ipe D, Schwartz KE: Healing of NSAID-induced gastric ulcers with a synthetic prostaglandin analog (enprostil). Am J Gastroenterol 1994, 89:1014-1020

14. Sturm A, Dignass AU: Modulation of gastrointestinal wound repair and inflammation by phospholipids. Biochim Biophys Acta 2002, 1582:282-288.

15. Dimberg J, Gustafson-Svard C, Westrom B, Tagesson C, Soderkvist P: Group I phospholipase $A_{2}$ mRNA expression in rat glandular stomach and pancreas. Ontogenic development and effects of cortisone acetate. Biochim Biophys Acta 1992, 1130:47-51.

16. Evans RJ, Surprenant $A$ : Effects of phospholipase $A_{2}$ inhibitors on coupling of alpha 2-adrenoceptors to inwardly rectifying potassium currents in guinea-pig submucosal neurones. Br J Pharmacol 1993, 110:591-596.

17. AOAC: Official methods of analysis of the association of official analytical chemists. 15th edition. Arlington, VA: Association of Official Analytical Chemists, 1990.

18. Yildirim A, Mavi A, Kara A: Determination of antioxidant and antimicrobial activities of Rumex crispus L. extracts. J Agric Food Chem 2001, 49:4083-4089.

19. Zhu QH, Hackman RM, Ensunsa JL, Holt RR, Keen CL: Antioxidant activities of oolong tea. J Agric Food Chem 2002, 50:6929-6934.

20. Kuo YH, Yeh DB, Pan BS: Rapid photometric assay evaluating antioxidative activity in edible plant material. J Agric Food Chem 1999, 47:3206-3209.

21. Halliwell B, Gutteridge JMC, Arurma Ol: The deoxyribose method: a simple "test-tube" assay for determination of rate constants for reactions of hydroxyl radicals. Anal Bioch 1987, 165:215-219.

22. Dinis TCP, Madeira VMC, Almeida LM: Action of phenolic derivatives (acetaminophen, salicylate, and 5-aminosalicylate) as inhibitors of membrane lipid peroxidation and as peroxyl radical scavengers. Arch Biochem Biophys 1994, 315:161-169.

23. Lowry OH, Rosebrough NJ, Farr AL, Randall RJ: Protein measurement with the Folin phenol reagent. J Biol Chem 1951, 193(1):265-275.

24. Sofowora A: Screening for bioactive agents. In Medicinal Plants and Traditional Medicine in Africa. New York: Wiley; 1982:128-161.

25. Wang L, Yen J-H, Liang H-H, Wu M-J: Antioxidant effects of methanol ectracts form lotus plumule and blossom (Nelumbo nucifera Gertn.). Food Drug Anal 2003, 11(1):60-66.

26. Porto CD, Calligaris S, Cellotti E, Nicoli MC: Antiradical properties of commercial cognacs assessed by the DPPH test. J Agric Food Chem 2000 48:4241-4245.

27. Tandon R, Mukherjee N, V. K, Dixit VK, R. Khanna R, Khanna HD: Lipid peroxidation levels in peptic ulcer and gastric carcinoma. Indian J Physiol Pharmacol 2006, 50(1):83-86.

28. Olaleye SA, Adaramoye OA, Erigbali PP, Adeniyi OS: Lead exposure increases oxidative stress in the gastric mucosa of $\mathrm{HCL} /$ ethanol-exposed rats. World J Gastroenterol 2007, 13(38):5121-5126.

29. Demir S, Yilmaz M, Köseoğlu M, Akalin N, Aslan D, Aydin A: Role of free radicals in peptic ulcer and gastritis. Turk J Gastroenterol 2003, 14(1):39-43.

30. Chan FKL, Leung WK: Peptic-ulcer disease. Lancet 2002, 360(9337):933-961.

31. Siregar IM, Miladiyah I: Protective effects of Cyclea barbata Miers leaves against aspirin-induced gastric ulcer in mice. Univ Med 2011, 30(2):88-94
32. Middleton EJr, Kandaswami C: The impact of plant flovonoids on mammalian biology: implications for immunity, inflammation and cancer. In The flavonoids-Advances in Research since 1986. Edited by Harbourne JB. Boca Raton: Chapman and Hall; 1994:619-652.

33. Wallace $J L$, Devchand PR: Emerging roles for cyclooxygenase-2 in gastrointestinal mucosal defense. Br J Pharmacol 2005, 145(3):275-282.

34. Ma L, del Soldato $P$, Wallace JL: Divergent effects of new cyclooxygenase inhibitors on gastric ulcer healing: Shifting the angiogenic balance. Proc Natl Acad Sci USA 2002, 99(20):13243-13247.

35. Asako H, Kubes P, Wallace J, Gaginella T, Wolf RE, Granger DN: Indomethacin-induced leukocyte adhesion in mesenteric venules: role of lipoxygenase products. Am J Physiol Gastrointest Liver Physiol 1992, 262: G903-G908.

36. Asako H, Kubes P, Wallace J, Wolf RE, Granger DN: Modulation of leukocyte adhesion in rat mesenteric venules by aspirin and salicylate. Gastroenterology 1992, 103:146-152.

37. Winrow VR, Winyard PG, Morris CJ, Blake DR: Free radicals in inflammation: second messengers and mediators of tissue destruction. Brit Med Bull 1993, 49:506-522.

38. Ni Z, Okeley NM, Smart BP, Gelb MH: Intracellular actions of group IIA secreted phospholipase $A_{2}$ and group IVA cytosolic phospholipase $A_{2}$ contribute to arachidonic acid release and prostaglandin production in rat gastric mucosal cells and transfected human embryonic kidney cells. J Biol Chem 2006, 281(24):16245-16255.

39. Balsinde J, Balboa MA, Insel PA, Dennis EA: Regulation and inhibition of phospholipase A2. Annu Rev Pharmacol Toxicol 1999, 39:175-189.

40. Dadzie-Mensah J: Modulation of eicosanoids biosyntheses in vivo as a mechanism-based evaluation of putative anti-inflammatory plant extracts. MPhil Thesis: University of Ghana, Department of Biochemistry; 2000.

41. Otamiri T, Tagesson C: Role of phospholipase $A_{2}$ and oxygenated free radicals in mucosal damage after small intestinal ischemia and reperfusion. Am J Surg 1989, 157:562-565

42. Boros M, Karacsony G, Kaszaki J, Nagy S: Reperfusion mucosal damage after complete intestinal ischemia in the dog: the effects of antioxidant and phospholipase $A_{2}$ inhibitor therapy. Surgery 1993, 113:184-191.

doi:10.1186/1472-6882-12-65

Cite this article as: Nartey et al: Antioxidant and gastric cytoprotective prostaglandins properties of Cassia sieberiana roots bark extract as an anti-ulcerogenic agent. BMC Complementary and Alternative Medicine 2012 12:65.

\section{Submit your next manuscript to BioMed Central and take full advantage of:}

- Convenient online submission

- Thorough peer review

- No space constraints or color figure charges

- Immediate publication on acceptance

- Inclusion in PubMed, CAS, Scopus and Google Scholar

- Research which is freely available for redistribution 